Jurnal Ilmu Ilmu Agribisnis: Journal of Agribusiness Science, 9(4), November 2021

\title{
ANALISIS PENDAPATAN USAHATANI ANGGOTA KOPERASI DAN NILAI TAMBAH PRODUK OLAHAN KOPI DI KOPERASI AGRO PANCA BHAKTI KABUPATEN LAMPUNG BARAT
}

\author{
(Income Farming Analysis of Cooperative Members and Value Added of Processed Product of Coffee at \\ Cooperative Agro Panca Bhakti in West Lampung Regency)
}

Fenti Gasanova, Dyah Aring Hepiana Lestari, Rabiatul Adawiyah

Jurusan Agribisnis, Fakultas Pertanian, Universitas Lampung, J1. Prof. Dr. Soemantri Brojonegoro No. 1 Bandar Lampung 35141,e-mail: dyah.aring@fp.unila.ac.id

\begin{abstract}
This research aims to analyze income farming of cooperative members and added value of processed products of coffee at cooperative Agro Panca Bhakti. This research was purposively conducted at Cooperative Agro Panca Bhakti, Sekincau, West Lampung Regency from May to July 2018 with 34 respondents cooperative members and 4 respondents cooperative management. The data of this research were collected by using case study method and were analyzed descriptively by income farming analysis and value-added method by Hayami. The results of this research showed that the average of income based on total cost per year received by cooperative members was Rp11.012.188,82 per hectare. Processed products of coffee at cooperative Agro Panca Bhakti was viable development because it has positive added value.
\end{abstract}

Keywords: coffee, income farming, value added

Received : 4 December 2019 Revised: 17 December 2019 Accepted:13 January $2020 \quad$ DOI: http://dx.doi.org/10.23960/jiia.v9i4.5394

\section{PENDAHULUAN}

Pembangunan sektor pertanian menjadi fokus pembangunan ekonomi nasional. Menurut BPS (2017), kontribusi sektor pertanian, kehutanan, dan perikanan terhadap produk domestrik bruto (PDB) Indonesia merupakan tertinggi ketiga dengan nilai 12,80 persen. Salah satu komoditas unggulan dalam subsektor perkebunan adalah kopi. Kopi merupakan produk yang mempunyai peluang pasar yang baik di dalam negeri maupun luar negeri (Rahardjo 2012).

Provinsi Lampung memiliki luas areal perkebunan kopi terbesar kedua di Pulau Sumatera setelah Provinsi Sumatera Selatan dengan produksi kopi sebanyak 131.854,00 ton pada tahun 2015 dengan jenis kopi robusta. Kabupaten Lampung Barat memiliki luas areal perkebunan kopi terluas dan penyumbang produksi kopi robusta tertinggi di Provinsi Lampung dengan kontribusi produksi sebesar 47,81 persen terhadap total produksi kopi di Provinsi Lampung (Direktorat Jenderal Perkebunan 2016).

Kecamatan Pagar Dewa merupakan wilayah dengan produksi dan luas areal tertinggi di Kabupaten Lampung Barat, sedangkan wilayah dengan produktivitas paling tinggi di Kabupaten
Lampung Barat adalah Kecamatan Kebun Tebu. Wilayah penghasil kopi robusta tertinggi kedua di Kabupaten Lampung Barat adalah Kecamatan Air Hitam, namun luas areal kebun kopi robusta tertinggi kedua adalah Kecamatan Sekincau. Hal ini menunjukkan bahwa terdapat beberapa wilayah yang memiliki luas areal tinggi tetapi produktivitasnya rendah. Selain produktivitas yang rendah, masalah yang dihadapi oleh petani kopi di Kabupaten Lampung Barat adalah harga jual di tingkat petani yang rendah.

Harga jual yang diterima oleh petani menjadi rendah karena petani hanya sebagai penerima harga. Kebanyakan petani kopi Lampung Barat menjual produk kopi dalam bentuk produk primer yaitu kopi berasan (coffee beans) dan tidak ada perbedaan harga antara kopi dengan kualitas yang baik dan buruk. Adanya ikatan sosial dan ekonomi antara petani dengan para pedagang menyebabkan petani sulit menjual langsung produknya dan mengakses pasar (Marlina, Dharmawan, dan Purnamadewi 2017).

Produktivitas lahan dan harga jual di tingkat petani yang rendah secara tidak langsung berpengaruh terhadap pendapatan usahatani kopi menjadi rendah. Hal ini mendorong petani mencari alternatif yang lebih menguntungkan dalam 
menjual dan memasarkan hasil panen. Salah satu cara yang dilakukan petani kopi di Kecamatan Sekincau Kabupaten Lampung Barat adalah bergabung menjadi anggota Koperasi Agro Panca Bhakti. Koperasi Agro Panca Bhakti merupakan koperasi pertanian yang beranggotakan petani kopi yang ada di Kecamatan Sekincau, Kabupaten Lampung Barat. Keberadaan Koperasi Agro Panca Bhakti diharapkan dapat membantu para petani kopi di Kecamatan Sekincau dalam memasarkan dan mengolah biji kopi yang didapatkan petani dari menjalankan usahatani kopi.

Salah satu unit usaha yang dijalankan Koperasi Agro Panca Bhakti adalah pengolahan biji kopi menjadi produk olahan seperti kopi roasting dan kopi bubuk. Kegiatan pengolahan ini bertujuan untuk menghasilkan nilai tambah (value added) dari biji kopi berasan (coffee beans) hasil panen anggotanya. Berdasarkan uraian tersebut maka tujuan penelitian ini adalah untuk menganalisis pendapatan usahatani kopi anggota koperasi dan nilai tambah yang diperoleh dari pengolahan biji kopi pada Koperasi Agro Panca Bhakti.

\section{METODE PENELITIAN}

Penelitian ini dilaksanakan di Koperasi Agro Panca Bhakti Kecamatan Sekincau Kabupaten Lampung Barat dengan menggunakan metode studi kasus. Responden penelitian terdiri dari 34 anggota dan 4 pengurus koperasi. Anggota koperasi menjadi responden untuk menganalisis pendapatan usahatani kopi dalam setahun terakhir. Pengurus koperasi menjadi responden untuk menganalisis nilai tambah pada unit usaha pengolahan biji kopi Koperasi Agro Panca Bhakti. Pengumpulan data penelitian ini dilakukan pada Bulan Mei hingga Juli 2018.

Data yang digunakan terdiri dari data primer dan data sekunder. Data primer adalah data yang didapatkan melalui wawancara langsung dengan responden menggunakan daftar pertanyaan (kuesioner) mengenai biaya dan penerimaan dalam usahatani kopi dan pengolahan biji kopi. Data sekunder adalah data yang diperoleh dari lembaga atau instansi, publikasi dan pustaka lainnya yang terkait dan relevan dengan penelitian ini. Analisis deskriptif kuantitatif digunakan untuk menganalisis pendapatan dan nilai tambah. Cara yang digunakan untuk menghitung pendapatan sama seperti yang digunakan Rahim dan Hastuti (2008).

$\pi=\mathrm{Y}$. Py $-\sum$ Xi. Pxi - BTT
Keterangan:

$\pi=$ Pendapatan usahatani kopi

$\mathrm{Y}=$ Produksi kopi $(\mathrm{kg})$

Py = Harga per satuan produksi kopi $(\mathrm{Rp} / \mathrm{Kg})$

$\mathrm{Xi}=$ Faktor produksi usahatani kopi $(\mathrm{i}=1,2,3, . . \mathrm{n})$

Pxi $=$ Harga faktor produksi ke $\mathrm{i}(\mathrm{Rp})$

$\mathrm{BTT}=$ Biaya tetap total $(\mathrm{Rp})$

Analisis data berikutnya adalah $\mathrm{R} / \mathrm{C}$ untuk mengetahui kelayakan usahatani yang dijalankan anggota koperasi dalam setahun yang dapat dirumuskan sebagai berikut.

$\mathrm{R} / \mathrm{C}=\mathrm{TR} / \mathrm{TC}$

Keterangan:

$\mathrm{R} / \mathrm{C}=$ Nisbah penerimaan dan biaya

$\mathrm{TR}=$ Total revenue atau penerimaan total $(\mathrm{Rp})$

$\mathrm{TC}=$ Total cost atau biaya total $(\mathrm{Rp})$

Kriteria pengambilan keputusan adalah:

1) Jika $R / C>1$, maka suatu usaha mengalami keuntungan.

2) Jika $\mathrm{R} / \mathrm{C}<1$, maka suatu usaha mengalami kerugian.

3) Jika $\mathrm{R} / \mathrm{C}=1$, maka suatu usaha mengalami impas.

Produk olahan yang dihasilkan Koperasi Agro Panca Bhakti terdiri dari empat jenis dan menggunakan peralatan yang sama. Menurut Bustami dan Nurlella (2009) perhitungan joint cost diperlukan terutama bila perusahaan menghasilkan produk lebih dari satu atau terdiri dari beberapa produk. Biaya yang dihitung adalah biaya yang digunakan secara bersama oleh produk bersama. Pada penelitian ini biaya bersama yang dikeluarkan dalam proses produksi olahan kopi adalah biaya overhead yaitu biaya penyusutan alat, biaya listrik, dan pajak.

Metode alokasi joint cost yang digunakan pada penelitian ini adalah dengan menggunakan metode nilai jual relatif yaitu harga jual diketahui pada saat titik pisah. Dasar pemikiran metode ini adalah bahwa harga jual suatu produk merupakan perwujudan biaya-biaya yang dikeluarkan dalam mengolah produk tersebut. Jika salah satu produk terjual lebih tinggi daripada produk yang lain, hal ini karena biaya yang dikeluarkan untuk produk tersebut lebih banyak bila dibandingkan dengan produk yang lain. Alokasi joint cost dengan metode harga jual diketahui pada saat titik pisah dapat dirumuskan sebagai berikut:

$$
\begin{aligned}
& \text { Alokasi } \\
& \text { Joint Cost }
\end{aligned}=\frac{\sum \text { nilai jual }}{\sum \text { nilai jual B }} \times \text { biaya bersama...(3) }
$$


Keterangan :

Nilai jual $A=$ Nilai jual masing-masing produk

Nilai jual $\mathrm{B}=$ Nilai jual keseluruhan produk

Nilai tambah yang dihasilkan unit usaha pengolahan Koperasi Agro Panca Bhakti dapat dihitung dengan menggunakan metode Hayami seperti yang dilakukan oleh Salsabilla, Haryono, dan Syarief (2019) serta Anggraeni, Lestari, dan Indriani (2017). Kriteria nilai tambah (NT) adalah sebagai berikut:

1) Jika NT $>0$, berarti pengembangan unit usaha pengolahan kopi memberikan nilai tambah (positif).

2) Jika NT $<0$, berarti pengembangan unit usaha pengolahan kopi tidak memberikan nilai tambah (negatif).

\section{HASIL DAN PEMBAHASAN}

\section{Karakteristik Responden}

Pengurus koperasi yang menjadi responden penelitian terdiri dari ketua koperasi, sekretaris koperasi, kepala unit usaha produksi, dan kepala unit usaha penjualan. Pengurus koperasi berdasarkan umur masuk dalam katagori usia produktif dan tingkatan pendidikan pengurus Koperasi Agro Panca Bhakti tergolong cukup tinggi yaitu SMA dan S1.

Karakteristik anggota koperasi dilihat dari umur, tingkat pendidikan, pekerjaan sampingan, jumlah anggota keluarga, pengalaman berusahatani, luas lahan dan status penguasaan lahan. Umur anggota koperasi berkisar antara 28 - 70 dengan rata-rata umur 45 tahun. Menurut Mantra (2004) usia produktif berkisar 15 sampai 64 tahun, oleh karena itu 97,06 persen anggota koperasi berada pada usia produktif. Tingkat pendidikan terbanyak anggota koperasi berada pada tingkat pendidikan SMA sebesar 41,18 persen. Pekerjaan sampingan terbanyak anggota koperasi adalah petani sayuran dengan persentase sebesar 50,00 persen. Rata-rata jumlah anggota keluarga terbanyak anggota koperasi berada pada kisaran 3-4 orang dengan persentase sebesar 76,47 persen.

Berdasarkan pengalaman berusahatani, sebesar 47,06 persen anggota koperasi memiliki pengalaman usahatani antara 5-21 tahun. Sebagian besar anggota koperasi yaitu 44,12 persen memiliki luas lahan antara 0,51-1,00 hektar. Status kepemilikan lahan akan berpengaruh terhadap pendapatan dan biaya yang dikeluarkan oleh anggota koperasi. Status kepemilikan lahan yang diusahakan seluruh anggota koperasi adalah milik sendiri, sehingga anggota koperasi tidak perlu lagi membayar biaya sewa lahan atau membagi hasil pendapatan usahataninya.

\section{Penggunaan Sarana Produksi (Input)}

Sarana produksi adalah input yang dibutuhkan untuk kegiatan usahatani kopi yaitu pupuk, pestisida, peralatan pertanian, dan tenaga kerja. Setiap anggota koperasi menghasilkan produksi yang berbeda bergantung dengan luas kebun usahatani, penggunaan input, dan pengelolaan kebunnya. Semakin besar luas kebun dengan input yang digunakan optimal dan pengelolaan kebun sesuai standar (baik), maka produksi tanaman kopi akan semakin tinggi.

Penggunaan pupuk pada kegiatan usahatani kopi bertujuan untuk menambahkan unsur hara tanah sehingga mempercepat pertumbuhan dan salah satu usaha untuk meningkatkan produksi kopi. Jenis pupuk yang digunakan anggota koperasi terdiri atas pupuk kimia (Urea, NPK phonska, $\mathrm{KCl}, \mathrm{ZA}$, dan NPK Mutiara) dan pupuk organik (pupuk kandang). Jumlah pupuk yang paling banyak digunakan adalah pupuk kandang karena harganya yang sangat murah. Rata-rata biaya pupuk yang dikeluarkan anggota koperasi dalam setahun adalah sebesar Rp912.141,52 per hektar. Biaya pupuk yang paling tinggi adalah NPK Phonska karena pupuk ini merupakan jenis pupuk kimia yang jumlah penggunaannya paling tinggi dan termasuk golongan pupuk subsidi.

Pestisida adalah bahan kimia yang digunakan untuk mengendalikan serangan hama dan penyakit tanaman pada saat kegiatan usahatani, sementara herbisida adalah jenis pestisida yang digunakan untuk mengendalikan pertumbuhan gulma atau tanaman pengganggu. Pestisida yang digunakan anggota koperasi adalah Regent dan Fastac, sedangkan herbisida yang digunakan adalah Roundup, Gramaxone, Kleenup, dan Zenus. Ratarata biaya pestisida yang dikeluarkan anggota koperasi dalam setahun adalah Rp459.133,28 per hektar. Jenis pestisida yang paling banyak digunakan adalah herbisida merek roundup. Penggunaan pestisida ini bertujuan untuk memberantas gulma secara kimiawi.

Peralatan yang digunakan anggota koperasi memiliki umur ekonomis, harga dan manfaat yang berbeda. Nilai harga, jumlah dan umur ekonomis alat-alat yang digunakan dapat digunakan untuk 
menghitung biaya penyusutan dari masing-masing alat tersebut. Nilai penyusutan dihitung dengan menggunakan metode garis lurus dengan asumsi bahwa peralatan tidak dapat digunakan lagi setelah melewati umur teknis. Sprayer, cangkul, dan parang atau golok digunakan pada saat pemeliharaan tanaman. Ginjar merupakan sebutan anggota koperasi untuk keranjang yang terbuat dari anyaman rotan digunakan untuk menampung kopi hasil petikan pada saat panen dan terpal digunakan pada saat melakukan penanganan pascapanen. Biaya penyusutan peralatan dalam setahun milik anggota koperasi adalah sebesar Rp192.738,97.

Tenaga kerja usahatani kopi terdiri dari petani beserta keluarga dan tenaga kerja luar keluarga yang berperan dalam usahatani. Tenaga kerja dibagi lagi menjadi tenaga kerja pria dan tenaga kerja wanita. Besarnya tenaga kerja yang digunakan dalam usahatani dihitung dalam satuan hari orang kerja (HOK) dengan standar jam kerja 8 jam kerja per hari dan rata-rata tingkat upah yang berlaku yaitu Rp50.000,00 per orang.

Pada penelitian in, hampir seluruh anggota koperasi tetap mempekerjakan pekerja lainnya untuk membantu dalam kegiatan usahatani terutama saat pemanenan. Hal ini dikarenakan luas lahan yang digarap cukup luas untuk dikerjakan hanya menggunakan tenaga kerja dalam keluarga, selain itu anggota koperasi memiliki pekerjaan sampingan selain menjadi petani kopi.

\section{Produksi, Harga Jual, dan Penerimaan}

Berdasarkan hasil penelitian, rata-rata produksi kopi robusta yang dihasilkan oleh anggota koperasi sebesar 1.011,76 kg biji kopi berasan (coffee beans) dengan rata-rata luas lahan usahatani sebesar 1,33 hektar. Jika dikonversikan ke dalam satu hektar maka produksi kopi sebesar 760,22 kg biji kopi berasan (coffee beans) dengan rata-rata harga kopi yang diterima anggota koperasi perkilogram sebesar $\mathrm{Rp} 23.617,65$ per $\mathrm{kg}$.

Penerimaan merupakan hasil perkalian antara total produksi (tanaman kopi dan tanaman sela) yang dihasilkan dikalikan dengan harga jual (tanaman kopi dan tanaman sela), sehingga semakin tinggi produksi dan harga jual maka penerimaan yang diperoleh akan semakin besar. Tanaman sela merupakan tanaman yang sengaja ditanam oleh petani pada lahan kosong di sela tanaman kopi. Manfaat tanaman sela adalah untuk meningkatkan efisiensi penggunaan lahan dan sumber penghasilan tambahan bagi petani kopi. Tanaman sela yang digunakan oleh anggota koperasi adalah tanaman lada, papaya, cabai rawit, dan jeruk sate. Hasil perhitungan menunjukkan bahwa rata-rata penerimaan anggota koperasi sebesar Rp24.988.150,12 per 1,33 hektar atau Rp18.775.626,61 per hektar.

\section{Analisis Pendapatan Usahatani Kopi}

Analisis pendapatan usahatani digunakan untuk mengetahui gambaran umum struktur biaya, penerimaan dan pendapatan dari kegiatan usahatani yang dijalankan. Analisis pendapatan usahatani ini menggunakan hasil perhitungan ratarata dari anggota koperasi dengan luas lahan ratarata 1,33 hektar dalam periode satu tahun. Hasil dari analisis ini dapat menjadi gambaran umum mengenai pendapatan yang diperoleh anggota koperasi dari hasil budidaya kopi robusta yang dilakukan. Analisis pendapatan usahatani kopi anggota Koperasi Agro Panca Bhakti dapat dilihat pada Tabel 1.

Berdasarkan data pada Tabel 1. diketahui bahwa rata-rata pendapatan atas biaya total yang diperoleh per tahun sebesar Rp14.655,927,77 dan pendapatan atas biaya tunai per tahun yang diperoleh anggota koperasi sebesar Rp19.985.799,09 per 1,33 hektar luas lahan. Untuk mengetahui pendapatan tunai per hektar, maka dilakukan konversi lahan menjadi 1 hektar sehingga rata-rata pendapatan atas biaya tunai yang diperoleh sebesar Rp15.016.954,02 per tahun per hektar.

Berdasarkan hasil perhitungan maka usahatani kopi menguntungkan bagi anggota Koperasi Agro Panca Bhakti karena nilai $\mathrm{R} / \mathrm{C}$ yang diperoleh lebih dari satu, yaitu 5,00 atas biaya tunai dan 2,42 atas biaya total. Hasil penelitian ini sejalan dengan penelitian yang dilakukan Tania, Widjaya, dan Suryani (2019) di Kecamatan Air Hitam Kabupaten Lampung Barat yang menyatakan bahwa usahatani kopi di Desa Gunung Terang berdasarkan luasan lahan 2,19 hektar dan per hektar sudah menguntungkan dan layak untuk diusahakan dengan nilai $\mathrm{R} / \mathrm{C}>1$.

\section{Bahan Baku dan Bahan Penunjang}

Salah satu unit usaha Koperasi Agro Panca Bhakti adalah unit usaha produksi yang melakukan kegiatan pengolahan biji kopi berasan menjadi kopi roasting dan kopi bubuk kemasan. Produk yang dihasilkan terdiri dari kopi roasting premium, kopi bubuk premium, kopi bubuk grade "Eka", dan kopi bubuk grade "Teri". 
Tabel 1. Analisis pendapatan usahatani kopi anggota Koperasi Agro Panca Bhakti Tahun 2018

\begin{tabular}{|c|c|c|c|c|c|}
\hline \multirow{2}{*}{ Uraian } & \multirow{2}{*}{$\begin{array}{c}\text { Harga } \\
\text { (Rp/satuan) }\end{array}$} & \multicolumn{2}{|c|}{ Usahatani kopi per 1,33 ha } & \multicolumn{2}{|c|}{ Usahatani kopi per 1 ha } \\
\hline & & Jumlah & Total nilai (Rp) & Jumlah & Total nilai $(\mathrm{Rp})$ \\
\hline \multicolumn{6}{|l|}{ Penerimaan } \\
\hline Produksi kopi (kg) & $23.617,65$ & $1.011,76$ & $23.895 .501,73$ & 760,22 & $17.954 .631,13$ \\
\hline Produksi lada (Rp) & $38.125,00$ & 10,54 & $401.761,25$ & 7,92 & $301.875,86$ \\
\hline Produksi cabai rawit(Rp) & $20.285,71$ & 32,68 & $662.937,14$ & 24,56 & $498.118,52$ \\
\hline Produksi jeruk sate (kg) & $5.000,00$ & 5,59 & $27.950,00$ & 4,20 & $21.001,10$ \\
\hline Total penerimaan $(\mathrm{Rp})$ & - & - & $24.988 .150,12$ & - & $18.775 .626,61$ \\
\hline \multicolumn{6}{|l|}{ Biaya produksi } \\
\hline \multicolumn{6}{|l|}{ I. Biaya tunai } \\
\hline Pupuk Urea (Kg) & $2.092,31$ & 129,41 & $270.769,23$ & 97,24 & $203.450,91$ \\
\hline Pupuk Phonska (Kg) & $2.953,33$ & 180,88 & $534.205,88$ & 135,91 & $401.392,27$ \\
\hline Pupuk $\mathrm{KCl}(\mathrm{Kg})$ & $2.800,00$ & 10,29 & $28.823,53$ & 7,73 & $21.657,46$ \\
\hline Pupuk ZA (Kg) & $2.040,00$ & 50,00 & $102.000,00$ & 37,57 & $76.640,88$ \\
\hline Pupuk Mutiara (Kg) & $10.000,00$ & 5,88 & $58.823,53$ & 4,42 & $44.198,90$ \\
\hline Pupuk Kandang (Kg) & 300,00 & 691,18 & $207.352,94$ & 519,34 & $155.801,10$ \\
\hline Roundup (L) & $74.204,55$ & 3,41 & $253.168,45$ & 2,56 & $190.226,02$ \\
\hline Gramaxone (L) & $67.266,67$ & 1,59 & $106.835,29$ & 1,19 & $80.274,03$ \\
\hline Kleen Up (L) & $62.000,00$ & 1,97 & $122.176,47$ & 1,48 & $91.801,10$ \\
\hline Regent (L) & $303.846,15$ & 0,18 & $54.960,41$ & 0,14 & $41.296,22$ \\
\hline Fastac $(\mathrm{L})$ & $163.076,92$ & 0,42 & $68.588,24$ & 0,32 & $51.535,91$ \\
\hline Biaya Transportasi Pupuk (Rp) & - & - & $28.794,12$ & - & $21.635,36$ \\
\hline Biaya Transportasi Pestisida (Rp) & - & - & $7.411,76$ & - & $5.569,06$ \\
\hline TK Luar Keluarga (HOK) & $50.000,00$ & 50,14 & $2.506 .985,29$ & 37,67 & $1.883 .701,66$ \\
\hline Biaya sewa huller (Rp/tahun) & - & - & $505.882,35$ & - & $380.110,50$ \\
\hline Biaya angkut (Rp/tahun) & - & - & $75.147,06$ & - & $56.464,09$ \\
\hline Pajak (Rp/tahun) & - & - & $70.426,47$ & - & $52.917,13$ \\
\hline Total biaya tunai & - & - & $5.002 .351,03$ & - & $3.758 .672,60$ \\
\hline \multicolumn{6}{|l|}{ II. Biaya diperhitungkan } \\
\hline TK dalam keluarga (HOK) & $50.000,00$ & 36,20 & $1.809 .926,47$ & 27,20 & $1.359 .944,75$ \\
\hline Sewa lahan (Rp/Ha/tahun) & $2.500 .000,00$ & 1,33 & $3.327 .205,88$ & 1,00 & $2.500 .000,00$ \\
\hline Penyusutan alat (Rp/tahun) & - & - & $192.738,97$ & - & $144.820,44$ \\
\hline Total biaya diperhitungkan & - & - & $5.329 .871,32$ & - & $4.004 .765,19$ \\
\hline III. Total biaya produksi & - & - & $10.332 .222,35$ & - & $7.763 .437,79$ \\
\hline \multicolumn{6}{|l|}{ Pendapatan } \\
\hline a. Pendapatan atas biaya tunai & - & - & 19.985.799,09 & - & $15.016 .954,02$ \\
\hline b. Pendapatan atas biaya total & - & - & $14.655 .927,77$ & - & $11.012 .188,82$ \\
\hline \multicolumn{6}{|l|}{$\mathrm{R} / \mathrm{C}$} \\
\hline a. $\mathrm{R} / \mathrm{C}$ atas biaya tunai & - & - & 5,00 & - & 5,00 \\
\hline b. R/C atas biaya total & - & - & 2,42 & - & 2,42 \\
\hline
\end{tabular}

Bahan baku kopi roasting premium dan kopi bubuk premium adalah biji kopi fully washed, sedangkan kopi bubuk grade "Eka" dan kopi bubuk grade "Teri” adalah biji kopi asalan.

Biji kopi fully washed merupakan biji kopi beras yang dihasilkan dari penanganan pasca panen proses basah dan telah difermentasi, sedangkan biji kopi asalan adalah biji kopi beras yang dihasilkan dari penanganan pasca panen secara natural process (tidak melalui proses pencucian). Koperasi Agro Panca Bhakti mendapatkan bahan baku dari simpanan wajib anggota (berupa $5 \mathrm{~kg}$ biji kopi fully washed per anggota untuk setahun) dan membeli secara langsung kepada anggota koperasi atau petani kopi lainnya di sekitar wilayah
Koperasi Agro Panca Bhakti. Biji kopi fully washed dibeli dengan harga Rp35.000,00 per kg, sedangkan biji kopi asalan dibeli dengan harga Rp23.000,00 per kg.

Bahan penunjang atau bahan baku pendukung adalah bahan-bahan yang digunakan sebagai pelengkap dalam pembuatan produk agar memperoleh hasil yang lebih baik, misalnya bahan untuk cita rasa, kualitas, dan penampilan atau daya tarik produk. Bahan penunjang atau pendukung pada Koperasi Agro Panca Bhakti adalah karung, kayu bakar, bubuk vanili, plastik bening, bahan bakar mesin (BBM), kemasan, dan stiker. Jumlah penggunaan bahan penunjang disesuaikan dengan jumlah penggunaan bahan baku utama. 


\section{Peralatan}

Koperasi Agro Panca Bhakti menggunakan peralatan yang masih tergolong sederhana, namun masih memadai dan layak digunakan. Peralatan berupa tampah, pengayak, bak plastik, dan ayakan bambu hanya digunakan untuk proses produksi kopi bubuk grade "Eka" dan kopi bubuk grade "Teri" saja. Hal ini dikarenakan pada produk kopi roasting premium dan kopi bubuk premium tidak dilakukan proses pensortiran dan pencucian. Peralatan seperti oven dan tirisan, timbangan digital, dan hand sealer digunakan untuk produksi seluruh produk olahan kopi, sedangkan mesin penggiling tidak digunakan pada proses produksi kopi roasting premium karena produk yang dihasilkan hanya berupa biji kopi utuh yang tidak digiling menjadi bubuk. Untuk menghitung biaya penyusutan per produk diperlukan perhitungan alokasi joint cost. Alokasi joint cost dapat dilihat pada Tabel 2.

Biaya penyusutan seluruh peralatan per produk dan total biaya penyusutan seluruh peralatan pada Koperasi Agro Panca Bhakti dapat dilihat pada Tabel 3. Data pada Tabel 3 menunjukkan bahwa total biaya penyusutan peralatan pada Koperasi Agro Panca Bhakti adalah Rp163.636,96 per bulan. Persentase biaya penyusutan terbesar adalah produk kopi bubuk grade "Eka" yaitu sebesar 43,65 persen dari total biaya penyusutan atau senilai Rp71.420,04 per bulan.

\section{Tenaga Kerja}

Jumlah tenaga kerja yang digunakan memiliki pengaruh besar dalam keberlangsungan usaha. Tenaga kerja yang digunakan Koperasi Agro Panca Bhakti seluruhnya berasal dari anggota Koperasi Agro Panca Bhakti yang terdiri dari 2 orang pria dan 2 orang wanita. Biaya tenaga kerja yang dibayar oleh Koperasi Agro Panca Bhakti yaitu sebesar Rp60.000,00 per hari. Sistem pembayaran upah tenaga kerja yang diterapkan oleh Koperasi Agro Panca Bhakti yaitu setiap satu kali proses produksi, upah tenaga kerja langsung dibayarkan. Total upah tenaga kerja per bulan pada Koperasi Agro Panca Bhakti dapat dilihat pada Tabel 4.

Data pada Tabel 4 menunjukkan bahwa total biaya tenaga kerja yang dikeluarkan untuk menghasilkan seluruh produk olahan kopi adalah sebesar Rp2.640.000,00 per bulan. Persentase penggunaan biaya tenaga kerja dengan biaya tertinggi adalah pada proses produksi kopi bubuk grade "Eka" dengan persentase sebesar 47,73 persen dengan penggunaan tenaga kerja sebesar 21,00 HOK dan biaya tenaga kerja yang digunakan sebesar Rp1.260.000,00 per bulan. Besarnya biaya tersebut disebabkan oleh penggunaan tenaga kerja dalam proses produksi kopi bubuk grade "Eka" yang membutuhkan waktu yang lebih lama dalam setiap proses produksinya karena bahan baku yang digunakan lebih banyak dibandingkan dengan tiga jenis produk lainnya.

Tabel 2. Alokasi joint cost dengan metode nilai jual relatif yaitu dari harga jual diketahui pada saat titik pisah

\begin{tabular}{lcccc}
\hline \multicolumn{1}{c}{ Jenis peralatan } & $\begin{array}{c}\text { Kopi bubuk } \\
\text { premium }(\%)\end{array}$ & $\begin{array}{c}\text { Kopi roasting } \\
\text { premium }(\%)\end{array}$ & $\begin{array}{c}\text { Kopi bubuk grade "Eka" } \\
(\%)\end{array}$ & $\begin{array}{c}\text { Kopi bubuk grade } \\
\text { "Teri”" (\%) }\end{array}$ \\
\hline Tampah & - & - & 69,76 & 30,24 \\
Pengayak & - & - & 69,76 & 30,24 \\
Bak plastik & - & - & 69,76 & 30,24 \\
Saringan bambu & - & - & 69,76 & 30,24 \\
Oven, tungku, dan tirisan & 39,58 & 5,36 & 38,41 & 16,65 \\
Mesin penggiling kopi & 41,82 & - & 40,58 & 17,59 \\
Timbangan digital & 39,58 & 5,36 & 38,41 & 16,65 \\
Hand sealer & 39,58 & 5,36 & 38,41 & 16,65 \\
Biaya listrik & 39,58 & 5,36 & 38,41 & 16,65 \\
Biaya pajak & 39,58 & 5,36 & 38,41 & 16,65 \\
\hline
\end{tabular}

Tabel 3. Total biaya penyusutan seluruh peralatan per bulan pada Koperasi Agro Panca Bhakti

\begin{tabular}{lcc}
\hline \multicolumn{1}{c}{ Jenis Produk } & $\begin{array}{r}\text { Penyusutan peralatan per bulan } \\
(\text { Rp/bulan) }\end{array}$ & $\begin{array}{c}\text { Persentase biaya penyusutan } \\
(\%)\end{array}$ \\
\hline Kopi bubuk premium & $56.557,12$ & 34,56 \\
Kopi roasting premium & $5.632,09$ & 3,44 \\
Kopi bubuk grade "Eka" & $71.420,04$ & 43,65 \\
Kopi bubuk grade "Teri" & $30.027,72$ & 18,35 \\
\hline Total & $163.636,96$ & 100,00 \\
\hline
\end{tabular}


Tabel 4. Penggunaan tenaga kerja per bulan pada Koperasi Agro Panca Bhakti

\begin{tabular}{lcrr}
\hline \multicolumn{1}{c}{ Jenis produk } & $\begin{array}{c}\text { Tenaga Kerja } \\
(\text { HOK/bulan })\end{array}$ & $\begin{array}{c}\text { Biaya Tenaga Kerja } \\
(\text { Rp/bulan })\end{array}$ & $\begin{array}{c}\text { Persentase biaya tenaga kerja } \\
(\%)\end{array}$ \\
\hline Kopi bubuk premium & 8,20 & 492.000 & 18,64 \\
Kopi roasting premium & 0,80 & 48.000 & 1,82 \\
Kopi bubuk grade "Eka" & 21,00 & 1.260 .000 & 47,73 \\
Kopi bubuk grade "Teri" & 14,00 & 840.000 & 31,82 \\
\hline \multicolumn{1}{c}{ Total } & 44,00 & 2.640 .000 & 100,00 \\
\hline
\end{tabular}

\section{Analisis Nilai Tambah}

Analisis nilai tambah dilakukan untuk mengetahui peningkatan nilai tambah dari pengolahan biji kopi berasan menjadi kopi roasting dan kopi bubuk. Nilai tambah kopi roasting, kopi bubuk premium, kopi bubuk grade "Eka" dan kopi bubuk grade "Teri" dihitung berdasarkan hasil produksi masingmasing produk selama satu bulan. Analisis nilai tambah tidak hanya dipengaruhi oleh jumlah produksi melainkan juga dipengaruhi oleh jumlah penggunaan bahan baku, harga bahan baku dan sumbangan input lain. Analisis nilai tambah pada unit usaha pengolahan Koperasi Agro Panca Bhakti dapat dilihat pada Tabel 5.

Data pada Tabel 5 menunjukkan bahwa faktor konversi masing-masing produk olahan biji kopi bernilai kurang dari satu. Nilai faktor konversi tersebut menunjukkan bahwa setiap produk olahan kopi yang dihasilkan mengalami penyusutan dari bahan baku karena kandungan air pada biji kopi akan menghilang. Produk dengan nilai faktor konversi tertinggi adalah kopi roasting premium yaitu sebesar 0,91 artinya adalah setiap satu kilogram kopi beras fully washed yang digunakan akan menghasilkan $0,91 \mathrm{~kg}$ kopi roasting premium. Nilai konversi kopi roasting premium lebih besar dibandingkan produk lainnya karena bahan baku yang digunakan memiliki kualitas yang lebih baik dan juga tidak memerlukan proses penggilingan, sehingga bahan baku yang terbuang saat proses produksi lebih sedikit dibandingkan produk lainnya.

Koefisien tenaga kerja menunjukkan rasio antara banyaknya tenaga kerja yang terlibat dalam satuan HOK dengan jumlah bahan baku yang diolah.

Tabel 5. Analisis nilai tambah masing-masing produk olahan biji kopi pada Koperasi Agro Panca Bhakti

\begin{tabular}{|c|c|c|c|c|c|c|}
\hline \multirow[b]{2}{*}{ No } & Variabel & \multirow[t]{2}{*}{ Rumus } & \multicolumn{4}{|c|}{ Olahan biji kopi } \\
\hline & Output, Input, dan Harga & & $\begin{array}{c}\text { Kopi } \\
\text { bubuk } \\
\text { premium }\end{array}$ & $\begin{array}{c}\text { Kopi } \\
\text { roasting } \\
\text { premium }\end{array}$ & $\begin{array}{c}\text { Kopi } \\
\text { bubuk } \\
\text { Eka }\end{array}$ & $\begin{array}{c}\text { Kopi } \\
\text { bubuk } \\
\text { Teri }\end{array}$ \\
\hline 1 & Output (Kg/Bulan) & $\mathrm{A}$ & 93,00 & 15,00 & 128,00 & 78,00 \\
\hline 2 & Bahan Baku (Kg/Bulan) & B & 103,50 & 16,50 & 160,00 & 120,00 \\
\hline 3 & Tenaga Kerja (HOK/Bulan) & $\mathrm{C}$ & 8,20 & 0,80 & 21,00 & 14,00 \\
\hline 4 & Faktor Konversi & $\mathrm{D}=\mathrm{A} / \mathrm{B}$ & 0,90 & 0,91 & 0,80 & 0,65 \\
\hline 5 & Koefisien Tenaga Kerja & $\mathrm{E}=\mathrm{C} / \mathrm{B}$ & 0,08 & 0,05 & 0,13 & 0,12 \\
\hline 6 & Harga Output (Rp/Kg) & $\mathrm{F}$ & $120.000,00$ & $100.000,00$ & $80.000,00$ & $70.000,00$ \\
\hline \multirow[t]{2}{*}{7} & $\begin{array}{l}\text { Upah Rata-rata Tenaga Kerja } \\
\text { (Rp/HOK) }\end{array}$ & $\mathrm{G}$ & $60.000,00$ & $60.000,00$ & $60.000,00$ & $60.000,00$ \\
\hline & \multicolumn{2}{|c|}{ Pendapatan dan Nilai Tambah } & & & & \\
\hline 8 & Harga Bahan Baku (Rp/Kg) & $\mathrm{H}$ & $35.000,00$ & $35.000,00$ & $23.000,00$ & $23.000,00$ \\
\hline 9 & Sumbangan Input Lain $(\mathrm{Rp} / \mathrm{Kg})$ & I & $21.032,04$ & $8.605,38$ & $25.622,56$ & $9.042,84$ \\
\hline 10 & Nilai Output & $\mathrm{J}=\mathrm{D} \times \mathrm{F}$ & $107.826,09$ & $90.909,09$ & $64.000,00$ & $45.500,00$ \\
\hline \multirow[t]{2}{*}{11.} & a. Nilai Tambah & $\mathrm{K}=\mathrm{J}-\mathrm{I}-\mathrm{H}$ & $51.794,05$ & $47.303,71$ & $15.377,44$ & $13.457,16$ \\
\hline & b. Rasio Nilai Tambah & $\mathrm{L} \%=(\mathrm{K} / \mathrm{J}) \times 100 \%$ & 48,03 & 52,03 & 24,03 & 29,58 \\
\hline \multirow[t]{2}{*}{12.} & a. Imbalan Tenaga Kerja & $\mathrm{M}=\mathrm{E} \times \mathrm{G}$ & $4.753,62$ & $2.909,09$ & $7.875,00$ & $7.000,00$ \\
\hline & b. Bagian Tenaga Kerja & $\mathrm{N} \%=(\mathrm{M} / \mathrm{K}) \times 100 \%$ & 4,41 & 3,20 & 12,30 & 15,38 \\
\hline \multirow[t]{2}{*}{13.} & a. Keuntungan & $\mathrm{O}=\mathrm{K}-\mathrm{M}$ & $47.040,42$ & $44.394,62$ & $7.502,44$ & $6.457,16$ \\
\hline & b. Tingkat Keuntungan & $\mathrm{P} \%=(\mathrm{O} / \mathrm{K}) \times 100 \%$ & 90,82 & 93,85 & 48,79 & 47,98 \\
\hline \multicolumn{7}{|c|}{ Balas Jasa untuk Faktor Produksi } \\
\hline \multirow[t]{4}{*}{14} & Margin & $\mathrm{Q}=\mathrm{J}-\mathrm{H}$ & $72.826,09$ & $55.909,09$ & $41.000,00$ & $22.500,00$ \\
\hline & a. Keuntungan & $\mathrm{R}=\mathrm{O} / \mathrm{Q} \times 100 \%$ & 64,59 & 79,41 & 18,30 & 28,70 \\
\hline & b. Tenaga Kerja & $\mathrm{S}=\mathrm{M} / \mathrm{Q} \times 100 \%$ & 6,53 & 5,20 & 19,21 & 31,11 \\
\hline & c. Input Lain & $\mathrm{T}=\mathrm{I} / \mathrm{Q} \times 100 \%$ & 28,88 & 15,39 & 62,49 & 40,19 \\
\hline
\end{tabular}


Produk dengan nilai koefisien tenaga kerja terbesar adalah kopi bubuk grade "Eka" yaitu sebesar 0,13 artinya adalah banyaknya tenaga kerja yang digunakan untuk mengolah satu kilogram kopi bubuk grade "Eka" adalah 0,130 HOK.

Data pada Tabel 5 menunjukkan bahwa produk yang memiliki kontribusi keuntungan paling tinggi pada Koperasi Agro Panca Bhakti adalah kopi bubuk premium dengan nilai Rp47.040,42 per kilogram. Nilai tambah tertinggi adalah pada produk kopi bubuk premium sebesar Rp51.794,05 per kg bahan baku, sedangkan kopi bubuk grade "Teri" memiliki nilai tambah terendah.

Berdasarkan kriteria nilai tambah, maka dapat dikatakan bahwa Koperasi Agro Panca Bhakti memberikan nilai tambah (positif) karena NT $>0$. Hasil penelitian ini sejalan dengan penelitian Noviantari, Hasyim, dan Rosanti (2015) di Provinsi Lampung yang menyatakan bahwa agroindustri kopi luwak di Provinsi Lampung menguntungkan karena memberikan nilai tambah (positif) atau NT $>0$ dengan rata-rata nilai tambah yang diperoleh dari pengolahan satu kilogram buah kopi menjadi kopi luwak biji Rp67.123,95, kopi luwak biji menjadi kopi luwak bubuk Rp78.887,87 dan buah kopi menjadi kopi luwak bubuk Rp42.666,01.

\section{KESIMPULAN}

Berdasarkan hasil penelitian dapat disimpulkan bahwa rata-rata pendapatan usahatani kopi atas biaya tunai yang diperoleh anggota Koperasi Agro Panca Bhakti adalah sebesar Rp15.016.954,02 per hektar dalam setahun, sedangkan pendapatan atas biaya total yang diperoleh per hektarnya sebesar Rp11.012.188,82 dalam setahun. Usahatani kopi menguntungkan bagi anggota Koperasi Agro Panca Bhakti karena nilai R/C yang diperoleh lebih dari satu, yaitu nilai $\mathrm{R} / \mathrm{C}$ atas biaya tunai sebesar 5,00 dan $\mathrm{R} / \mathrm{C}$ atas biaya total sebesar 2,42. Unit usaha produksi produk olahan kopi pada Koperasi Agro Panca Bhakti menghasilkan nilai tambah yang positif dan layak untuk dikembangkan.

\section{DAFTAR PUSTAKA}

Anggraeni TS, Lestari DAH, dan Indriani Y. 2017. Analisis keragaan agroindustri tempe, manfaat ekonomi koperasi, dan tingkat partisipasinya sebagai anggota Primkopti Kabupaten
Pesawaran. Jurnal Ilmu Ilmu Agribisnis, 5 (3): 219-343. http://jurnal. fp.unila.ac.id/index.php/JIA/article/view/1640 /1466. [22 Agustus 2019].

BPS [Badan Pusat Statistik]. 2017. Pendapatan Domestik Bruto Triwulanan Atas Dasar Harga Konstan 2010 Menurut Lapangan Usaha (Miliar Rupiah), 2014-2017. BPS. Jakarta. https://www.bps.go.id/linkTableDina mis/view/id/827. [23 Oktober 2019].

Bustami B dan Nurlella. 2009. Akuntansi Biaya: Kajian Teori dan Aplikasi. Edisi Pertama. Cetakan Pertama. Mitra Wacana Media. Jakarta.

Direktorat Jendral Perkebunan. 2016. Statistik Perkebunan Indonesia: 2015-2017 Kopi. Direktorat Jendral Perkebunan. Jakarta.

Mantra IB. 2004. Demografi Umum. Penerbit Pustaka Pelajar. Yogyakarta.

Marlina L, Dharmawan AH, dan Purnamadewi YL. 2017. Peranan kopi rakyat terhadap perekonomian wilayah Kabupaten Lampung Barat. Jurnal Ilmu Ilmu Agribisnis, 5 (3): 292303. http://jurnal.fp.un ila.ac.id/index.php/JIA/issue/view/153. [15 Desember 2017].

Noviantari K, Hasyim AI, dan Rosanti N. 2015. Analisis rantai pasok dan nilai tambah agroindustri kopi luwak di Provinsi Lampung. Jurnal Ilmu Ilmu Agribisnis, 3 (1): 10-17. http://jurnal.fp.unila.ac.id /index.php/JIA/ article/ view/101 2/917. [17 November 2019].

Rahardjo P. 2012. Panduan Budidaya dan Pengolahan Kopi Arabika dan Robusta. Penebar Swadaya. Jakarta.

Rahim ABD dan Hastuti DRD. 2008. Pengantar, Teori dan Kasus Ekonomika Pertanian. Penebar Swadaya. Jakarta.

Salsabilla S, Haryono D, dan Syarief YA. 2019. Analisis pendapatan dan nilai tambah agroindustri keripik pisang di Desa Sungai Langka Kecamatan Gedong Tataan Kabupaten Pesawaran. Jurnal Ilmu Ilmu $\begin{array}{llll}\text { Agribisnis, } & 7 & \text { (1): }\end{array}$ http://jurnal.fp.unila.ac.id/index.php/JIA/articl e/view/3333/2554. [19 Oktober 2019].

Tania R, Widjaya S, Suryani A. 2019. Usahatani, pendapatan dan kesejahteraan petani kopi di Lampung Barat. Jurnal Ilmu Ilmu Agribisnis, $7 \quad$ (2): $\quad 149-156 . \quad$ http://ju rnal.fp.unila.ac.id/index.php/JIA/article/view/ 3374/2576. [19 Oktober 2019]. 